\section{Analysis of Video Images Using an Interactive Image Capture and Analysis System}

\author{
G.W. Stutte \\ Department of Horticulture, University of Maryland, College Park, \\ MD 20742
}

Additional index words. videography, stress

\begin{abstract}
Interactive Image Capture and Analysis System (ICAS) provides for realtime capture of video images using an imaging board and software in a personal computer. Through the use of selective filters on the video input source, images of specific reflective wavelengths are obtained and then analyzed for intensity distribution using interactive software designed for scientific agriculture. Conversion of video cameras into two-dimensional near real-time visual and near infrared (NIR) spectral sensors through the use of filters provides information on the physiological status of the tissue following ICAS analysis. However, caution must be observed to minimize equipment-induced artifacts during image acquisition and analysis.
\end{abstract}

Video imagery has broad application for research and management in the plant sciences, e.g., quantifying histochemical stains (Stutte, 1989), enhancing electronmicrographs (Hader, 1988), detecting stress (Stutte et. al., 1988a), or identifying variability within a field (Stutte et. al., 1988b). The advantages and disadvantages of video. imagery in the plant sciences were reviewed recently by several authors (Gausman, 1987; Hader, 1988; and Vlcek, 1983). Improvements in video-image technology have overcome many of the early disadvantages associated with video-imaging (Meisner, 1986; Everett, 1988). The introduction of CCD detectors into video cameras has provided the potential for near real-time visualization of NIR reflectance from vegetation (Manzer and Cooper, 1982; Curran, 1983; Gausman, 1977).

Video images have several advantages over traditional methods of analyzing and collecting data. First, data can be collected and analyzed almost simultaneously. Second, VHS tapes are inexpensive and provide a permanent record of results. Third, the video equipment is accessible, relatively inexpensive, and flexible. And finally, video imagery provides unique information that is difficult to obtain through alternate methods.

Because visual interpretation of images is highly subjective, interest has increased in the development of computer imaging and analysis systems for the plant sciences. Several digitalization boards are capable of transferring a video input into digital format;

Received for Publication 12 May 1989. Contribution no: 8022, Scientific Article no. A-4978 of The Maryland Agricultural Experiment Station. The cost of publishing this paper was defrayed in part by the payment of page charges. Under postal regulations, this paper therefore must be hereby marked advertisement solely to indicate this fact.

Abbreviations: ALC, automatic luminescence control; CCD, charged coupled device; ICAS, interactive Image Capture and Analysis System; NIR, near infrared; VCR, video cassette recorder. however, software that can provide appropriate analysis of the images has been lacking. An ICAS has been developed by Digital Image Acquisition Systems (Inglewood, Colo.) and Agri-Imaging Systems (Fayetteville, Ark.) in cooperation with the Dept. of Agronomy, Univ. of Arkansas, Fayetteville, and the Dept. of Horticulture, Univ. of Maryland, College Park. It consists of an imaging board with continuous grabbing, frame-averaging, and image-summing capabilities and software for digital image enhancement, pseudo-color image enhancement, (Macbeth, Baltimore). ICAS.

"Mean separation within rows using LSD at $P>0.1$.

"Macbeth Color Checker Chart (Macbeth, Baltimore). and quantification of intensity distribution, distance, and area. In spite of the capabilities of the system, the limitations associated with data acquisition must be recognized to interpret the image accurately.

The ICAS imaging board accepts any RS$170 \mathrm{~A}$ video input of $0.03 \mathrm{sec}$ per frame. Video images with high reflectance intensity contrast between target objects and nontarget background objects are ideal for analysis. Contrast can be achieved at the time of image acquisition (with filters), at the time of video processing (autogain), or at the time of processing (digital filtering or equalization). The purpose for acquiring an image can range from quantifying the DNA of a single cell to surveying a forest. When the reflectance characteristics of the target are known, a specific protocol is developed for data acquisition and analysis. Failure to target the image acquisition to the reflectance characteristics of the target will result in erroneous results.

The resolution required for analysis is determined by the information to be obtained. The fundamental purpose of image capture and analysis is to digitalize, store, and process an image and to extract information about a specific response. Trade-offs exist between memory storage and speed of processing, as well as pixel resolution and visual detail. An image with the resolution of $256 \times 256$ pixel can be digitalized in about one fourth the time needed for a $512 \times 512$ image and requires one fourth the storage space. The higher resolution of the $512 \times 512$ image is more important for human interpretation than

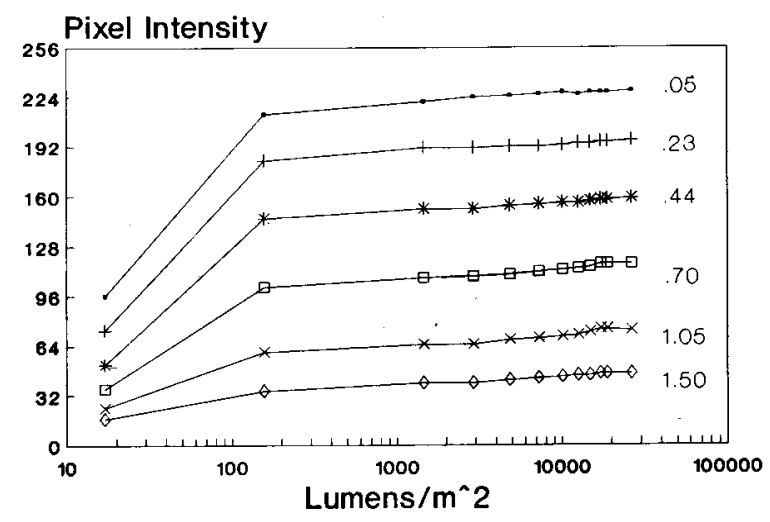

Fig. 1. Effect of incandescent light intensity on ICAS intensity values of optical density standards

Table 1. Effect of light quality on mean reflectance intensity determination from color standards using

\begin{tabular}{|c|c|c|c|c|c|}
\hline \multirow[b]{2}{*}{ Color" } & \multicolumn{3}{|c|}{ Hunter values $^{2}$} & \multicolumn{2}{|c|}{ Reflectance intensity ${ }^{x, y}$} \\
\hline & $\mathrm{L}$ & $\mathrm{a}$ & $\mathrm{b}$ & Incandescent & Fluorescent \\
\hline Blue & 27.5 & 9.1 & -49.3 & $79 \mathrm{a}$ & $74 \mathrm{a}$ \\
\hline Green & 47.8 & -23.3 & 20.3 & $123 \mathrm{~d}$ & $113 \mathrm{~d}$ \\
\hline Red & 33.1 & 40.7 & 12.6 & $90 \mathrm{~b}$ & $75 \mathrm{a}$ \\
\hline Yellow & 73.7 & 4.6 & 44.6 & $181 \mathrm{e}$ & $184 \mathrm{e}$ \\
\hline Magenta & 44.4 & 37.2 & -15.6 & $118 \mathrm{c}$ & $101 \mathrm{~b}$ \\
\hline Cyan & 46.7 & -20.9 & -20.2 & $119 \mathrm{c}$ & $106 \mathrm{C}$ \\
\hline
\end{tabular}

${ }^{2}$ Mean of three determinations with Spectrogard Color System (Pacific Scientific, Silver Spring, Md.). ${ }^{y} 150-\mathrm{W}$ photoflood incandescent or $40-\mathrm{W}$ cool-white fluorescent lamps at $7500 \mathrm{Im} \cdot \mathrm{m}^{-2}$ 

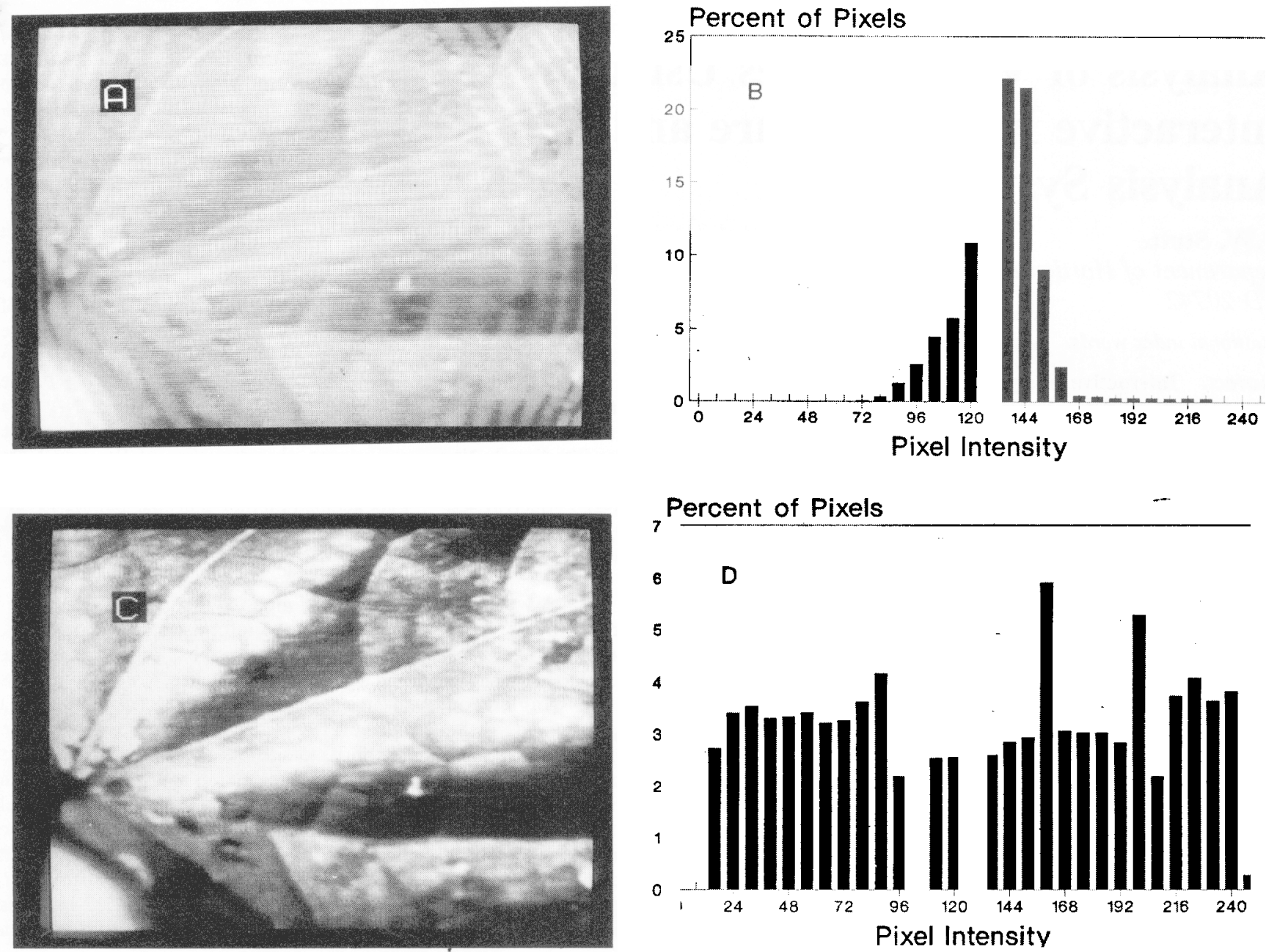

Fig. 2. Effect of digital equalization on intensity contrast and pixel distribution in philodendron leaf. (A) Original digital image of leaf, (B) intensity distribution histogram of leaf, (C) image following digital equalization, and (D) intensity distribution histogram following equalization.

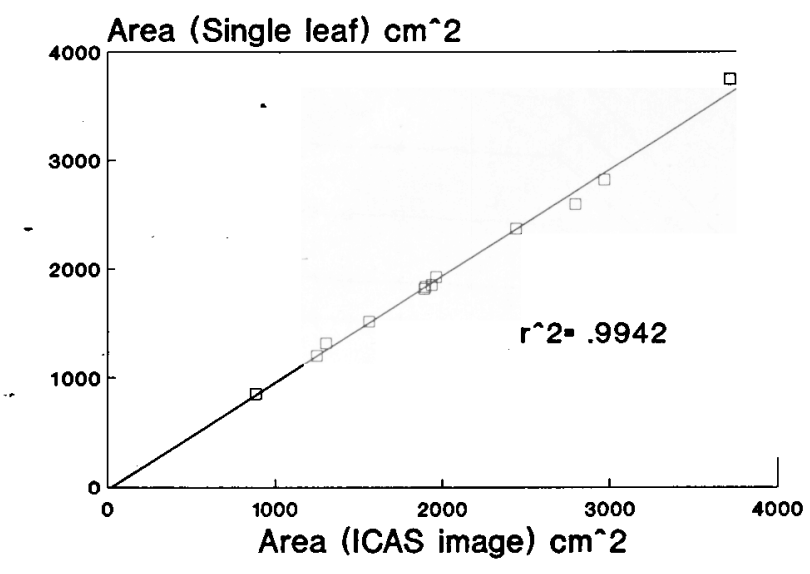

Fig. 3. Comparison of leaf area determination from single video image using ICAS and a LI-COR 3000 leaf area meter (mean number leaves per plant $=58$ ).

for computer analysis, however, since 256 $\times 256$ exceeds the resolution of most VCR tapes.

The VCR provides an inexpensive and convenient means for storing images for later processing. Assuming good-quality images are obtained by the camera, the quality of VCR images depends on two factors: 1) the degradation of the signal from camera to VCR and 2) the degradation of the signal during transfer to magnetic tape. Following the ac- quisition of an image by the camera, the individual signals that make up the red, blue, and green components of a color video signal are synchronized and combined into a composite signal, which is then transferred to the VCR. The transfer of the composite from the video camera to the video tape recorder can result in a 5\% to $10 \%$ loss of signal resolution to stray radiation and electromagnetic noise (Vlcek, 1988). This problem can be minimized by using shielded, high-quality cables and connectors. Unfortunately, image degradation during transfer from camera to magnetic tape results in significant loss of clarity and is not easily corrected. Although a theoretical limit of 485 vertical lines exists for each $1.3-\mathrm{cm}(0.5$-inch) VHS video tape frame, each field only has 242 lines resolution, and image noise and signal loss results in a functional resolution of 100 to 110 lines (Vlcek, 1988). Increased resolution can be obtained by using 1.9-crn (0.75-inch) VCR tape or a digital video recorder that records images electronically on 5 . 1-cm (2-inch) floppy disks or directly onto a video disk; both options are relatively expensive.

To obtain scientifically meaningful data, the reflectance characteristics of the target must correspond to the sensor sensitivity of the camera. A CCD camera detects light from 340 to $1100 \mathrm{~nm}$, with $>90 \%$ detector sensitivity in the 550 to $950-\mathrm{nm}$ range, which encompasses the green, red, and NIR regions of the electromagnetic spectrum. Saticon tubes, which detect light from 300 to $690 \mathrm{~nm}$, have greatest sensitivity in the blue region. Selective filters limit the wavelengths of light reaching the detector and provide a tool for customizing the sensor. For example, the reflectance characteristics of nitrogen stress are most apparent in the regions associated with "chlorophyll absorp- 
tion bands at $680 \mathrm{~nm}$ and reflections of NIR above $710 \mathrm{~nm}$ (Hoffer, 1978; Gausman, 1977). The use of filters increases image contrast between stressed and nonstressed plants and permits early detection of nitrogen stress (Stutteet al., 1988a).

This reduction of the total lumens reaching the detector activates autogain enhancement. Autogain is electronic signal amplification by the camera to maximize image contrast at low-light levels. This function, which is an asset when visualizing images for subjective interpretation, maybe asignificant source of error in the quantitative comparisonof images obtained With filters, since contrast is altered under low-light conditions. Thus, caution must be exercised when comparing images acquired under different lighting conditions.

Two very significant points must be conSidered when evaluating video images: 1) reflectance intensity is sensitive to light quality and 2) reflectance intensity is insensitive to light quantity.

The effect of light quality on reflectance intensity from standard color patches at 7500 $\mathrm{lm} \cdot \mathrm{m}^{-2}$ of 'fluorescent or incandescent lighting is shown in Table 1. When incandescent light is used as an illumination source, the magnitude of reflectance intensity is yellow $>$ green $>$ cyan $=$ magenta $>$ red $>$ blue . This magnitude differs from that of fluorescent lighting, where yellow > green $>$ cyan $>$ magenta $>$ red $=$ blue. Under fluorescent lights, the luminance signals for the primary colors blue and red are identical and cannot be differentiated. Likewise, magenta and cyan cannot be differentiated under incandescent lighting. These results demonstrate the need to use specific filters if differentiation based on color is to be accomplished digitally.

-Figure 1 illustrates the effect of light intensity on reflectance from an optical density standard. There is intensity saturation at 150 $\mathrm{lm} \cdot \mathrm{m}^{-1}$ that remains unchangEd even as light intensity increases over four orders of magnitude to $26,000 \mathrm{~lm} \cdot \mathrm{m}^{-2}$. From 17 to 150 $1 \mathrm{~m} \cdot \mathrm{m}^{1}$, autogain adjustments amplify differences. At the higher light intensities, ALC in the camera adjusts the iris width to control light reaching the detector. Together, Table 1 and Fig. 1 suggest that comparisons between treatments can be made only between images obtained under identical light-quality conditions, but that no significant alteration of relative intensity values will occur between 200 and $20,000 \mathrm{~lm} \cdot \mathrm{m}^{-2}$, permitting direct comparison of relative intensity changes on images obtained under different intensities.

The ICAS provides the flexibility to ex- tract meaningful comparative intensity distributions from targeted video images. The video signal enters the ICAS board via a RS-170A input and is digitalized in one of two formats: 320 horizontal pixels (picture elements $) \times 240$ vertical pixels or 256 horizontal $\times 240$ vertical pixels. The $320 \times$ 256 mode results in square pixels that facilitate distance and. area measurements. In both modes, the stored frame is $256 \times 256$ pixels $(65,536$ individual picture elements). The incoming RS-170A signal is digitalized to 256 gray levels that can be enhanced with pseudo-color. Pseudo-color enhancement permits the user to assign up to 256 individual colors to an image (one per gray scale intensity) from a palette of more than 16 million colors.

The ICAS software also has the capability to increase intensity contrast by the use of image equalization. Equalization of digital images can offset the tendency of autogain to concentrate differences in the center of the intensity range under low-contrast conditions. Equalization results in a "stretching" of intensities within a given region of an image to a maximum range of gray scales of 256 without altering the relative distribution of the intensities within the equalized region (Fig. 2). In other words, areas of low contrast are converted to areas of high contrast. Digital enhancement to identify lines, reduce extraneous background noise, increase contrast, or identify edges is possible through image-filtering with highpass, lowpass, or LaPacian filters. While filters are extremely powerful tools to extract specific information from an image, they alter the value of the individual pixel.

Procedures to increase contrast during image acquisition and digital enhancement facilitate quantification of intensity distribution. Digital intensity analysis is an inherently precise means to assess distance and area following proper calibration (Fig. 3). Histogram distribution of intensities in an area provide a precise determination of mean intensity. The standard deviation of the intensity distribution indicates image texture or uniformity. Under a given set of conditions, target areas are assigned to intensity ranges, thus permitting analysis of multiple image components simultaneously.

The tools provided by ICAS have resulted in rapid advances in the identification of production variability within cultivated fields (Stutte et al., 1988) and real-time analysis of net enzyme activity in developing peach (Stutte, 1989). Applications of videography to crop management and early stress detection in horticultural and agronomic crops have enormous potential to improve resource management by rapidly quantifying the physiological status of the plant.

\section{Literature Cited}

Curran, P.J. 1983. Estimating green LAI from multispectral aerial photography. Photo. Eng. \& Remote Sens. 49:1709-1720.

Everett, J.H; 1988. Introduction to videography. Historical overview, relation to remote sensing, advantages and disadvantages, p. 1-5. In: P. Mausel (cd.). Videography: First workshop. Amer. Sot. Photogram. \& Remote Sens., Falls Church, Va.

Gausman, H.W. 1977. Reflectance of leaf components. Remote Sens. Environ. 25:255-293.

Gausman, H.W. 1987. Photographic and video dramas of remote sensing with plants as thespians. Proc. 11th Biennial Wkshp. on Color Aerial Photography and Vldeography. Amer. Sot. Photogram. \& Remote Sens., Falls Church, Va. p. 5-20.

Hader, Donat-P. 1988. Computer-assisted image analysis in biological sciences. Proc. Indian Acad. Sci. 98:227-249.

Hoffer, R.M. 1978. Biological and physical considerations in applying computer-aided analysis techniques to remote sensing data, p. 227-288. In: P.H. Swain and S.M. Davis (eds.). Remote sensing: The quantitative approach. McGrawHill, New York.

Manzer, F.E. and G.R. Cooper. 1982. Use of portable video-taping for aerial infrared detection of potato disease. Plant Dis. 66:665-667.

Meisner, D.M. 1986. Fundamentals of airborne video remote sensing. Remote Sens. Environ. 19:63-79.

Stutte, G.W. 1989. Quantification of net enzymatic activity in developing peach fruit using computer video image analysis. HortScienee 23:113-115.

Stutte, C.A. and G.W. Stutte. 1988. An interactive image capture and analysis system (ICAS) for research and crop management, p. 151-159. In: P. Mausel (ed.). Videography: First workshop. Amer. Sot. Photogram. \& Remote Sens., Falls Church, Va.

Stutte, G.W., C.A. Stutte, and M.J. Newell. 1988a. Quantification of water and nitrogen stress in peach trees using ICAS computer video image analysis, p. 137-144. In: P. Mausel (ed.). Videography: First workshop. Amer. Sot. Photogram. \& Remote Sens., Falls Church, Va.

Stutte, C. A., G.W. Stutte, and L.O. Ashlock. 1988b. Yield verification in field crops using image capture and analysis system, p. 195-203. In: P. Mausel (ed.). Videography: First workshop. Amer. Soc. Photogram. \& Remote Sens., Falls Church, Va.

Vlcek, J. 1983. Videography: Some remote sensing applications. Proc. 49th Annu. Meeting, Amer. Sot. Photogram. \& Remote Sens., Washington, D.C. p. 63-69.

Vlcek, J. 1988. Nature of video images, p. 5-12. In: P. Mausel (cd.). Videography: First workshop. Amer. Soc. Photogram. \& Remote Sens., Falls Church, Va. 